\title{
Workplace Sexual Harassment: Potential Long-term Associations with Psychological Function in Older Adults
}

J Gen Intern Med 37(3):692-4

DOI: $10.1007 / \mathrm{s} 11606-021-06591-1$

(C) This is a U.S. government work and not under copyright protection in the U.S.; foreign copyright protection may apply 2021

\section{INTRODUCTION}

Over the past decade, growing public dialogue about workplace sexual harassment has raised questions about the consequences of these experiences on health. Although links between sexual harassment and short-term psychological distress have been reported, ${ }^{1,2}$ work in this area has largely focused on women, leaving open questions about gender differences in these experiences. Furthermore, research has also focused on working-aged adults, leaving little information about the prevalence and potential lasting impact of harassment in older adults. In this study, we examined associations between workplace sexual harassment exposure and psychological function in a national sample of largely retired older adults.

\section{METHODS}

We analyzed data from men and women aged 50 and older in the National Social Life, Health, and Aging Project (Wave 2), a cross-sectional, national probability sample of older community-dwelling adults, with home-based study visits conducted between August 2010 and May 2011 (response rate of $74 \%){ }^{3}$ The institutional review boards of the University of Chicago and NORC approved the protocol; participants provided informed consent.

Workplace sexual harassment was categorized as a positive response to the self-administered question, "Sometimes at work, men and women find themselves the object of unwanted sexual advances, propositions, or sexual discussions from coworkers or supervisors. The advances sometimes involve physical contact and sometimes just involve sexual conversations. Thinking about your entire life so far, has this ever happened to you?". Anxiety and depressive symptoms were

\section{Prior Presentations}

These findings have not been previously presented at any national or regional conferences, nor published elsewhere.

Received October 28, 2020

Accepted January 1, 2021

Published online January 19, 2021 identified using a modified Hospital Anxiety and Depression Scale-Anxiety Subscale (score $\geq 8)^{4}$ and an 11-item Center for Epidemiologic Studies Depression Scale (score $\geq 9){ }^{5}$ Sedative-hypnotics and antidepressants were categorized from review of prescribed medications during in-home interviews. Age, race/ethnicity, employment status, and education were self-reported, and body mass index was calculated from height and weight measured by trained study staff.

Descriptive analyses were used to describe and compare key variables. Weighted ${ }^{3}$ multivariable logistic regression models were used to relate workplace sexual harassment and mood and psychotropic medication use, adjusting for age, race/ethnicity, body mass index, and education. Given known differences in the prevalence of both exposures and outcomes, 1, 2, 6 all analyses were stratified by gender.

\section{RESULTS}

Among 2687 older men and women (mean age 71.50, SE .27), $18 \%(n=224)$ of men and close to $30 \%(n=422)$ of women endorsed a history of workplace sexual harassment (Table 1). Clinically significant anxiety and depressive symptoms were observed in $19.0 \%$ and $16.2 \%$ of men and $21.5 \%$ and $20.4 \%$ of women, respectively; $9.1 \%$ of men and $15.1 \%$ of women used sedative-hypnotics, and $10.7 \%$ of men and $18.3 \%$ of women used antidepressants. In adjusted analyses, no significant associations between sexual harassment and psychological function outcomes were detected among men. Women endorsing sexual harassment had higher odds of current depressive symptoms, anxiety, and sedative-hypnotic use (Table 2).

\section{DISCUSSION}

In this national sample of adults aged 50 and older, close to 1 in 5 men and 1 in 3 women reported lifetime workplace sexual harassment exposure. Furthermore, women reporting harassment were more likely to have clinically significant anxiety and depressive symptoms and to use sedative-hypnotics in older age. While the cross-sectional design of this study limits our ability to assess causality, these findings raise concerns about potential long-term psychological consequences of these common experiences and effects on high-risk medication use in older age, at least for older women. 
Table 1 Baseline Characteristics of Study Participants $(n=2687)$

\begin{tabular}{lcl}
\hline \hline & $\begin{array}{l}\text { Women } \\
(\boldsymbol{n}=\mathbf{1 4 9 4})\end{array}$ & $\begin{array}{l}\text { Men } \\
(\boldsymbol{n}=\mathbf{1 1 9 3})\end{array}$ \\
\hline Characteristic & $\begin{array}{l}n \text { (weighted } \\
\%)\end{array}$ & $\begin{array}{l}n \text { (weighted } \\
\%)\end{array}$ \\
Age (weighted mean, SE) & $71.06(.26)$ & $71.80(.31)$ \\
Body mass index (weighted & $32.54(3.28)$ & $29.59(.22)$ \\
mean, SE) & & \\
Race/ethnicity & & \\
Non-Latina White & $1101(82.8)$ & $910(84.92)$ \\
Black or African American & $201(8.0)$ & $121(5.54)$ \\
Latina or Hispanic & $149(6.2)$ & $131(6.96)$ \\
Other & $36(2.6)$ & $28(2.59)$ \\
Education & & \\
$\quad$ <High school & $244(13.7)$ & $213(14.12)$ \\
High school/GED & $388(26.2)$ & $268(21.71)$ \\
Some college & $538(38.5)$ & $340(28.72)$ \\
College or more & $324(21.6)$ & $372(35.44)$ \\
\hline
\end{tabular}

Missing values: age 0, race/ethnicity 7, education 0, BMI 66

This study provides new national data on workplace sexual harassment among older adults, addressing the paucity of research in this area. Similar associations between workplace

Table 2 Associations Between Mood Symptoms, Psychotropic Medication Use, and History of Workplace Sexual Harassment

\begin{tabular}{|c|c|c|c|}
\hline & $\begin{array}{l}\text { Workplace } \\
\text { sexual } \\
\text { harassment }\end{array}$ & $\begin{array}{l}\text { No workplace } \\
\text { sexual } \\
\text { harassment }\end{array}$ & $\begin{array}{l}\text { OR } \\
\text { (95\% } \\
\text { CI) }\end{array}$ \\
\hline Women & $\begin{array}{l}(n=422, \\
29.7 \%)\end{array}$ & $\begin{array}{l}(n=1072, \\
70.3 \%)\end{array}$ & \\
\hline Anxiety $^{\mathrm{a}}$ & $118(27.2)$ & 203 (18.3) & $\begin{array}{l}1.7 \\
(1.1- \\
2.6)\end{array}$ \\
\hline $\begin{array}{l}\text { Depressive } \\
\text { symptoms }\end{array}$ & $102(24.4)$ & $203(18.0)$ & $\begin{array}{l}1.9 \\
(1.4- \\
2.7)\end{array}$ \\
\hline $\begin{array}{l}\text { Sedative- } \\
\text { hypnotic use }\end{array}$ & $81(17.9)$ & $144(14.3)$ & $\begin{array}{l}1.5 \\
(1.1- \\
2.1)\end{array}$ \\
\hline $\begin{array}{l}\text { Antidepressant } \\
\text { use }^{\mathrm{d}}\end{array}$ & $90(22.3)$ & 184 (18.6) & $\begin{array}{l}1.2 \\
(0.9- \\
1.7)\end{array}$ \\
\hline Men & $\begin{array}{l}(n=224, \\
18.6 \%)\end{array}$ & $(n=969,81.4 \%)$ & \\
\hline Anxiety $^{\mathrm{a}}$ & $54(20.8)$ & 184 (18.6) & $\begin{array}{l}1.2 \\
(0.8- \\
1.8)\end{array}$ \\
\hline $\begin{array}{l}\text { Depressive } \\
\text { symptoms }\end{array}$ & $38(13.1)$ & $168(17.0)$ & $\begin{array}{l}0.8 \\
(0.5- \\
1.2)\end{array}$ \\
\hline $\begin{array}{l}\text { Sedative- } \\
\text { hypnotic use }\end{array}$ & $23(8.7)$ & $78(9.1)$ & $\begin{array}{l}1.0 \\
(0.6- \\
1.9)\end{array}$ \\
\hline $\begin{array}{l}\text { Antidepressant } \\
\text { use }^{\mathrm{d}}\end{array}$ & $28(11.5)$ & $103(10.5)$ & $\begin{array}{l}1.0 \\
(0.5- \\
1.9)\end{array}$ \\
\hline
\end{tabular}

Full information maximum likelihood models, adjusted for age, racelethnicity, BMI, and education. Weighted percents shown for all values. Note: Anxiety and depressive symptoms were slightly attenuated but still significant in women with further adjustment for antidepressant use and sedative-hypnotic use

${ }^{a} H A D S-A \geq 8$

${ }^{b}$ Short form $C E S-D \geq 9$

${ }^{c}$ Includes barbiturates; benzodiazepines; and miscellaneous anxiolytics, sedatives, and hypnotics based on review of prescribed medications

${ }^{d}$ Includes SSNRIs, SSRIs, miscellaneous antidepressants, monoamine oxidase inhibitors, phenylpiperazine antidepressants, tetracyclic antidepressants, and tricyclic antidepressants based on review of prescribed medications sexual harassment and mental health in women, but not men, have been previously reported in samples of reproductiveaged adults, ${ }^{1}$ though not seen in a prior study of midlife women. ${ }^{2}$ Potential explanations for these differences include gender differences in the perception and appraisal of harassment experiences. ${ }^{1,2}$ Limitations of the current study include an inability to determine the severity and chronicity of harassment experiences, as well as elapsed time since exposure. Additionally, clinical depression and anxiety diagnoses, as well as the duration and indication of medication use, cannot be determined from these data. Nevertheless, these findings highlight high lifetime prevalence of harassment exposure in older adults with potential links to late-life psychological function among older women, underscoring the need for research to investigate long-term consequences of sexual harassment across the lifespan.

Carolyn J. Gibson, $\mathrm{PhD}, \mathrm{MPH}^{1,2}$

Nadra Lisha, $P h D^{3}$

Pooja Lalchandani, $B A^{3}$

Alison J. Huang, MD, MAS ${ }^{3}$

${ }^{1}$ San Francisco VA Health Care System,

San Francisco, CA, USA

${ }^{2}$ Department of Psychiatry and Behavioral Sciences, University of California, San Francisco,

San Francisco, CA, USA

${ }^{3}$ Division of General Internal Medicine, Department of Medicine, University of California, San Francisco, San Francisco, CA, USA

Corresponding Author: Carolyn J. Gibson, PhD, MPH; San Francisco VA Health Care System, San Francisco, CA, USA (e-mail: Carolyn.Gibson2@va.gov).

Author Contributions No additional individuals contributed to this manuscript but do not meet the criteria for authorship.

Funding This research was supported by the resources and facilities of the San Francisco VA Medical Center and the University of California San Francisco (including VA Health Services Research \& Delivery CDA IK2 HXOO2402 (CJG) and National Institute of Aging K24AG068601 (AJH)). The initial study design, methods, subject recruitment, and data collection for NSHAP were funded by the National Institutes of Health, including the National Institute on Aging, the Office of Women's Health Research, the Office of AIDS Research, and the Office of Behavioral and Social Sciences Research (R01AG021487), and conducted by the non-partisan and objective research organization NORC at the University of Chicago. The sponsors were not involved in the analysis or interpretation of data; preparation, review, or approval of the manuscript; or the decision to submit the manuscript for publication.

\section{Compliance with Ethical Standards:}

Conflict of Interest: The authors have no other conflicts of interest to report.

Disclaimer: The content is solely the responsibility of the authors and does not necessarily represent the official views of the Department of Veterans Affairs. 


\section{REFERENCES}

1. Harnois CE, Bastos JL. Discrimination, Harassment, and Gendered Health Inequalities: Do Perceptions of Workplace Mistreatment Contribute to the Gender Gap in Self-reported Health? J Health Soc Behav. 2018;59(2):283-299. doi:https://doi.org/10.1177/0022146518767407

2. Thurston RC, Chang Y, Matthews KA, von Känel R, Koenen K. Association of Sexual Harassment and Sexual Assault With Midlife Women's Mental and Physical Health. JAMA Intern Med. Jan 2019;179(1):48-53. doi:https://doi.org/10.1001/jamainternmed.2018.4886

3. O'Muircheartaigh C, English N, Pedlow S, Kwok PK. Sample design, sample augmentation, and estimation for Wave 2 of the NSHAP J Gerontol B Psychol Sci Soc Sci. 2014;69 Suppl 2:S15-26. doi:https://doi.org/10. 1093/geronb/gbu053
4. Bjelland I, Dahl AA, Haug TT, Neckelmann D. The validity of the Hospital Anxiety and Depression Scale. An updated literature review. J Psychosom Res. 2002;52(2):69-77.

5. Kohout FJ, Berkman LF, Evans DA, Cornoni-Huntley J. Two shorter forms of the CES-D (Center for Epidemiological Studies Depression) depression symptoms index. J Aging Health. May 1993;5(2):179-93.

6. Moore TJ, Mattison DR. Adult Utilization of Psychiatric Drugs and Differences by Sex, Age, and Race. JAMA Intern Med. 2017;177(2):274275. doi:https://doi.org/10.1001/jamainternmed.2016.7507

Publisher's Note: Springer Nature remains neutral with regard to jurisdictional claims in published maps and institutional affiliations. 